\title{
Dissipation of Pre-Harvest Pesticides on 'Clementine' Mandarins after Open Field Application, and Their Persistence When Stored under Conventional Postharvest Conditions
}

\author{
Natalia Besil ${ }^{1}$, Verónica Cesio ${ }^{2}$, Eleana Luque ${ }^{3}$, Pedro Pintos ${ }^{3}$, Fernando Rivas ${ }^{3}$ and \\ Horacio Heinzen ${ }^{2, *}$ \\ 1 Grupo de Análisis de Contaminantes Trazas (GACT), Departamento de Química del Litoral, Facultad de \\ Química, CENUR Litoral Norte, UdelaR, Paysandú 60000, Uruguay; nbesil@fq.edu.uy \\ 2 Grupo de Análisis de Contaminantes Trazas (GACT), Cátedra de Farmacognosia y Productos Naturales, \\ Departamento de Química Orgánica, Facultad de Química, UdelaR, Montevideo 11800, Uruguay; \\ cs@fq.edu.uy \\ 3 Programa Nacional de Investigación Citrícola, Instituto Nacional de Investigación Agropecuaria INIA, \\ Estación Experimental Salto Grande, Camino al Terrible s/n, Salto 50000, Uruguay; \\ eluque@sg.inia.org.uy (E.L.); ppintos@sg.inia.org.uy (P.P.); cfrivas@sg.inia.org.uy (F.R.) \\ * Correspondence: heinzen@fq.edu.uy; Tel.: +598-2924-4068
}

Received: 13 October 2018; Accepted: 12 December 2018; Published: 18 December 2018

\begin{abstract}
The dissipation of field-applied difenoconazole, imidacloprid, pyraclostrobin and spinosad on Clementine mandarins (Citrus clementina Hort. ex Tan.) under controlled conditions throughout the citrus production chain was assessed. At harvest, 42 days after application, the dissipation of these pesticides were 80,92 , and $48 \%$ for difenoconazole, imidacloprid, pyraclostrobin, respectively, and spinosad was below the level of detectability. At day 28 after application, spinosad was no longer detected. The model equations that best describe the dissipation curves of these pesticides on Clementine mandarins showed different patterns. Their half-life on Clementine, calculated by the best-fitted experimental data, were 19.2 day (1st-order model) for difenoconazole, 4.1 day (Root Factor (RF) 1st-order model) for imidacloprid, 39.8 day (2nd-order model) for pyraclostrobin and 5.8 day (1st-order model) for spinosad. These results are the first record of pyraclostrobin persistence on mandarins, showing a longer half-life in this matrix than those reported for any other fruit. The treated fruit were harvested and submitted to the usual postharvest treatments: first, a hypochlorite drenching was performed; as a second step, imazalil and wax were applied, and then the mandarins were stored at $4{ }^{\circ} \mathrm{C}$. After 32 days, cold storage caused no significant effects on the residue levels of the four pesticides compared with those determined on freshly harvested mandarins. All residues were below their Codex and European Union (EU) maximum residue limit (MRL) for mandarin since the spray application day.
\end{abstract}

Keywords: pesticide residues; degradation dynamic; citrus; LC-MS/MS

\section{Introduction}

Citrus fruit are among the most widely produced and popular fruit in the world [1,2], due to their well-known health-promoting properties, their unique flavor, and versatility for combining with other ingredients to develop new foods. Citrus trees are very productive, and a normal 10 year old mandarin tree can produce $150-180 \mathrm{~kg}$ of fresh fruit. This productive capacity of citrus sustains the citrus fruit international business. The fresh fruit has a long half-life, which can be extended with cold 
storage, and the fruit can be sold overseas. Citrus are Uruguay's main fresh fruit export with sales in the international market as high as 110,000 tons per year. Orange, mandarin, and lemon represent 52, 34 , and $14 \%$, respectively, of the total fresh fruit volume exported, with Clementine the main mandarin cultivar exported [3]. Nevertheless, citrus plants are vulnerable to insects and fungal attack during the pre- and postharvest steps. In the field during the cropping season, citrus fruit are susceptible to insects such as Phyllocnistis citrella (citrus leafminer), the fruit fly, or fungi such as Alternaria spp. and Phyllosticta citricarpa (citrus black spot), which cause serious diseases that jeopardize overall productivity [4-6]. However, after harvest, the main citrus pest is green mold, Penicillium digitatum, which grows on the fruit even during cold storage $[7,8]$.

To enhance productivity and protect the crop against plagues and pests, different pesticides are currently applied at different stages of the production chain. In the field, when the fruit is still developing, fungicides and insecticides from different chemical families are applied. Among the fungicides, the most widely employed are the phthalimides captan and folpet, benzimidazoles such as carbendazim, and tebuconazole, an inhibitor of ergosterol biosynthesis. The insecticides currently applied are chlorpyrifos, an organophosphate, and neonicotinoids such as imidacloprid or the chitin biosynthesis inhibitor buprofezin [9]. Pesticide residues and their persistence on or in food are an important and well-known concern for human health and environmental safety. When a pesticide is applied, it not only reaches the target but also reaches other organisms in the ecosystem. Pesticides dissipate within the environment after application. The processes of pesticide dissipation are complex and depend on their physicochemical properties, but also in their degradability by biotic and abiotic process $[10,11]$. After the banning of the most persistent organochlorines, efforts have been made to ensure the degradability and minimal bioaccumulation of newer pesticides. Once their protective action is accomplished, they should dissipate. As there could be more than one mechanism acting on pesticide dissipation, it is generally assumed that the kinetics of these processes follows a pseudo 1st-order equation that depends solely on the concentration of the compound under study. This assumption allows the determination of the half-life (time needed to reduce the concentration of the pesticide in the matrix under study to $50 \%$ ), an important parameter that is used to establish the pre-harvest interval as well as the adjustment to accomplish the legal MRLs to ensure safe consumption [12]. A key issue for establishing accurate and safe pre-harvest intervals is to realize that pesticide dissipation depends not only on the chemical properties of the compound but also on the environmental conditions that rules their behavior. Temperature, moisture, rain, sunlight, and biota are the main parameters responsible for pesticide dissipation and they change from one region to another [11]. Many studies have reported the presence of imidacloprid [13,14], pyraclostrobin [15], and difenoconazole in oranges [16]. It is clearly established that the dissipation behavior of these compounds under field conditions depends on diverse factors, including plant species, chemical formulation, application method, weather conditions, and crop growth characteristics [17-19].

An extensive database of pesticide dissipation is available on the web. Lewis et al. [20] developed a dataset of pesticide dissipation rates in/on various plant matrices for the Pesticide Properties Database (PPDB). The influence of the specific part of the plant is highlighted, the leaves being the part that showed the greatest variations in the pesticide dissipation rates. A pesticide's mode of action plays a crucial role. Systemic pesticides suffer biotransformation and metabolism within the plant, but non-systemic ones can only be degraded by the epiphytic flora and the environmental conditions, which can change from one region to another and even from one cropping season to the next. The amount of epicuticular wax on the surface of the specific plant under study is also critical, and the amount depends on the water available to the plant. Water deficits trigger epicuticular wax biosynthesis, whereas epicuticular wax is thinner when the plant has good water supply. In addition, half-lives determined in greenhouses are different from those found in open field experiments. When the fruit are in greenhouses radiation is diminished, rainfall is nonexistent, while temperature can be controlled and, therefore, the pesticide half-life can change enormously $[17,18]$. Open field experiments are far more complicated to perform as the climatic conditions vary without any control, a situation 
that is avoidable in experiments performed in greenhouses. Another source of variation of pesticide half-life is postharvest treatment. Produce washing, hypochlorite baths or cold storage may have specific influences on the persistence of pesticides within the commodity. It has been demonstrated that washing reduced the lipophilic pesticide amount in leafy vegetables, but the same treatment had little effect in fruit with relatively high amounts of wax or hairs on their surface, where the pesticides dissolve and the lipophilic pesticide amount remains unchanged for longer periods. In general, cold storage diminishes pesticide dissipation by minimizing the viable microbiological flora, the lack of radiation inside the chamber and for slowing down all the chemical reactions that cause pesticide degradation. Consequently, dissipation studies for a given fruit in the specific growing conditions of the cropping region are necessary to determine if the established pre-harvest time ensures that residue levels are below the maximum residue limit (MRL). Several authors have reported on pesticide residues and their dissipation in citrus fruit, including pesticides such as flusilazole [21], 2.4 D [22], spirotetramat [23], spirodiclofen-pyridaben [24], and insect growth regulators [25]. Nevertheless, little attention has been paid to the effect of postharvest treatments on the level of the remaining residues of the pesticides applied in the field. In the case of the citrus production chain, fruit are washed and sanitized, followed by postharvest fungicide and protecting wax applications. The purpose of waxing is to impart a shiny appearance to the fruit and to reduce weight loss by slowing down senescence during storage [26]. The fruit thus treated is stored at $4{ }^{\circ} \mathrm{C}$ for some weeks and often shipped overseas. As has been pointed out, the artificial wax is another factor that influences the dissipation of pesticides from the fruit.

Among the crop-protecting agents employed in citrus production, pyraclostrobin and difenoconazole, two broad spectrum fungicides for citrus Alternaria brown spot control and citrus black spot control $[27,28]$ have been intensively applied. Difenoconazole belongs to the largest fungicide family: the triazoles. Difenoconazole acts by inhibition of the demethylation step at C-14 of lanosterol during ergosterol synthesis [29]. By contrast, pyraclostrobin is a strobilurin fungicide. Its mechanism of action is based on binding at the oxidation site of quinol (Qo) (or ubiquinol site) of cytochrome $b$ in the mitochondria and, therefore, it stops the transfer of electrons causing the inhibition of cellular respiration [30]. These fungicides also are transported within the plant. Difenoconazole is a systemic fungicide that is absorbed and translocated in a plant, whereas the strobilurins are quasi-systemic, as they diffuse translaminarly within a leaf, but do not spread throughout an entire whole plant. The number of applications per season is 1 and 1-2 for difenoconazole and pyraclostrobin, respectively.

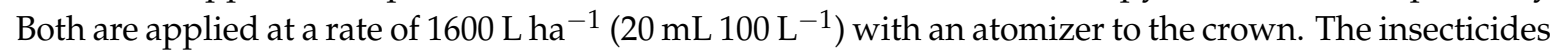
imidacloprid and spinosad are commonly sprayed for citrus leafminer control [4]. Imidacloprid is a neonicotinoid insecticide that targets the nicotinic acetylcholine receptor (nAChR). The union of the insecticide to the receptor causes a hyper-excitation of the nervous system and the death of the insect [31]. This systemic insecticide is commonly applied by painting the trunk, by irrigation or by spraying with an atomizer to the crown. Imidacloprid is applied twice per season at a rate of $30-50 \mathrm{~mL}$ $100 \mathrm{~L}^{-1}$ (irrigation or spray) or 1-3 $\mathrm{mL}$ tree $\mathrm{e}^{-1}$ (painting the trunk). Spinosad is a biological insecticide derived from the fermentation of the Actinomycete bacterium Saccharopolyspora spinosa [32], and is a natural mixture of spinosyn A and spinosyn D [33]. The mode of action of spinosad is over the nicotinic receptor, but the inhibition of the transmission of the nervous impulse does not occur at the nicotinic receptor itself. It also targets the Gamma-Aminobutyric Acid (GABA) receptor at the ion channels. This efficient insecticide is allowed in organic production, giving organic farmers an important tool to protect their production within the rules. The number of spinosad applications per season is 1 or 2 at a rate of $200-300 \mathrm{~L} \mathrm{ha}^{-1}\left(15 \mathrm{cc} \mathrm{L}^{-1}\right)$. The insecticide is applied using an atomizer to the crown.

Even though the residues and dissipation patterns of difenoconazole, imidacloprid, pyraclostrobin, and spinosad have been determined for apple, cabbage, cucumber, grapes and tomato, there are few studies regarding their dissipation in citrus species. The dissipation of imidacloprid in lemon and 
sweet orange was evaluated by Phartiyal et al. [34] and Singh et al., [35], but there are few records of the behavior of these four pesticides during mandarin pre-harvest field conditions.

The aims of this work were: (i) to evaluate the dissipation of difenoconazole, imidacloprid, pyraclostrobin and spinosad in Clementine fruit in field conditions; and (ii) to assess the influence of postharvest practices on the terminal residue levels of the four pesticides in whole fruit.

\section{Materials and Methods}

\subsection{Reagents and Apparatus}

Acetonitrile $(\mathrm{MeCN})$ and ethyl acetate (EtOAc) of High-Performance Liquid Chromatography (HPLC) quality were purchased from Sigma-Aldrich (Steinheim, Germany) and Pharmco Products Inc. (Brookfield, CT, USA), respectively. A Thermo Scientific (Marietta, OH, USA) EASYpure RoDi Ultrapure water purification system was used to obtain deionized water. Formic acid (HCOOH) p.a. $88 \%$ was obtained from Merck (Darmstadt, Germany). Sodium chloride ( $\mathrm{NaCl}$ ) was obtained from Carlo Erba (Arese, Italy). Anhydrous magnesium sulfate $\left(\mathrm{MgSO}_{4}\right)$ was purchased from Scharlau (Barcelona, Spain).

High purity reference standards $(>98 \%)$ were purchased from Dr. Ehrenstofer (Augsburg, Germany) and were stored at $-40{ }^{\circ} \mathrm{C}$. Stock standard solutions at $2000 \mu \mathrm{g} \mathrm{mL}{ }^{-1}$ were prepared by dissolving the standards in acetonitrile or ethyl acetate and stored in glass vials at $-40^{\circ} \mathrm{C}$. Working standard solutions were prepared by diluting the stock solutions with acetonitrile.

An ultrasonic bath Wisd WUC-A03H from Daihan Scientific Co. Ltd. (Seoul, Korea), a SL16 centrifuge from Thermo IEC HN-SII (Langenselbold, Germany), a vortex mixer Wisd VM 10 and a Turbovap ${ }^{\circledR}$ Biotage LV evaporator (Charlotte, NC, USA) were employed during the sample preparation step.

\subsection{Field and Postharvest Experiment}

The experiment was conducted with Clementine mandarin cv. 'Clemenules' (Citrus clementina Hort. ex Tan.), one of the most popular mandarins worldwide, a medium-sized, easy to peel mandarin, with a smooth and deep reddish orange rind color and parthenocarpic ability [36]. Pesticide applications were made to healthy adult trees of Clementine mandarin grafted onto Citrus trifoliata (L. Raf.) rootstock. The trial was conducted in Salto in the northern region of Uruguay at $31^{\circ} 16^{\prime} 45.47^{\prime \prime} \mathrm{S}$, $57^{\circ} 53^{\prime} 52.15^{\prime \prime} \mathrm{W}$ and an elevation of $41 \mathrm{~m}$. The experimental plots contained six trees per pesticide in a single row, with a tree size of $9 \mathrm{~m}^{3}$ in rows oriented N-NE; S-SW. The tree spacing was $2 \mathrm{~m}$ in the row and $5.5 \mathrm{~m}$ between rows. To assess the dissipation pattern of the selected agrochemicals, commercial formulations were sprayed separately with a Stihl SR450 backpack sprayer until reaching the drip point (approx. $6 \mathrm{~L}$ tree $^{-1}$ ). Each pesticide was applied around the tree. The formulations were applied using the same Good Agricultural Practices (GAPs) procedures employed in citrus production and at the recommended label rates. Table 1 shows the pesticide, active ingredients and rates used. The trials were initiated $42 \mathrm{~d}$ before harvest.

Table 1. Pesticides evaluated and rate per 100 L. European Union (EU) and Codex Alimentarius Maximum Residue Levels (MRL) for each analyte in mandarin. Vol: volume.

\begin{tabular}{ccccc}
\hline Commercial Formulation/Manufacturer & Active (g L $\left.{ }^{-\mathbf{1}}\right)$ & Vol (cc) & $\begin{array}{c}\text { EU MRL } \\
\mathbf{( m g ~ k g}^{-\mathbf{1}} \mathbf{)}\end{array}$ & $\begin{array}{c}\text { Codex MRL } \\
\mathbf{( m g ~ k g}^{-\mathbf{1}} \mathbf{)}\end{array}$ \\
\hline SCORE 250 EC/Syngenta & Difenoconazole 250 & 20 & 0.6 & 0.6 \\
SPINGARD 35F/Compañía Cibeles SA & Imidacloprid 350 & 50 & 1 & 1 \\
COMET/BASF & Pyraclostrobin 250 & 30 & 1 & 2 \\
TRACER I/Rutilan SA & Spinosad 480 & 20 & $0.3^{\mathrm{z}}$ & $0.3^{\mathrm{z}}$ \\
\hline
\end{tabular}

${ }^{\mathrm{z}}$ Spinosad residue definition for plant and animal commodities: sum of spinosyn A and spinosyn D. 
Meteorological conditions from the spray date to fruit harvest were monitored. The daily temperature $(24 \mathrm{~h}$ ), precipitation (effective amount of precipitation), \% relative humidity, and solar irradiation $\mathrm{x}$ relative Heliophany, under field conditions, were measured and are presented in Figure 1.
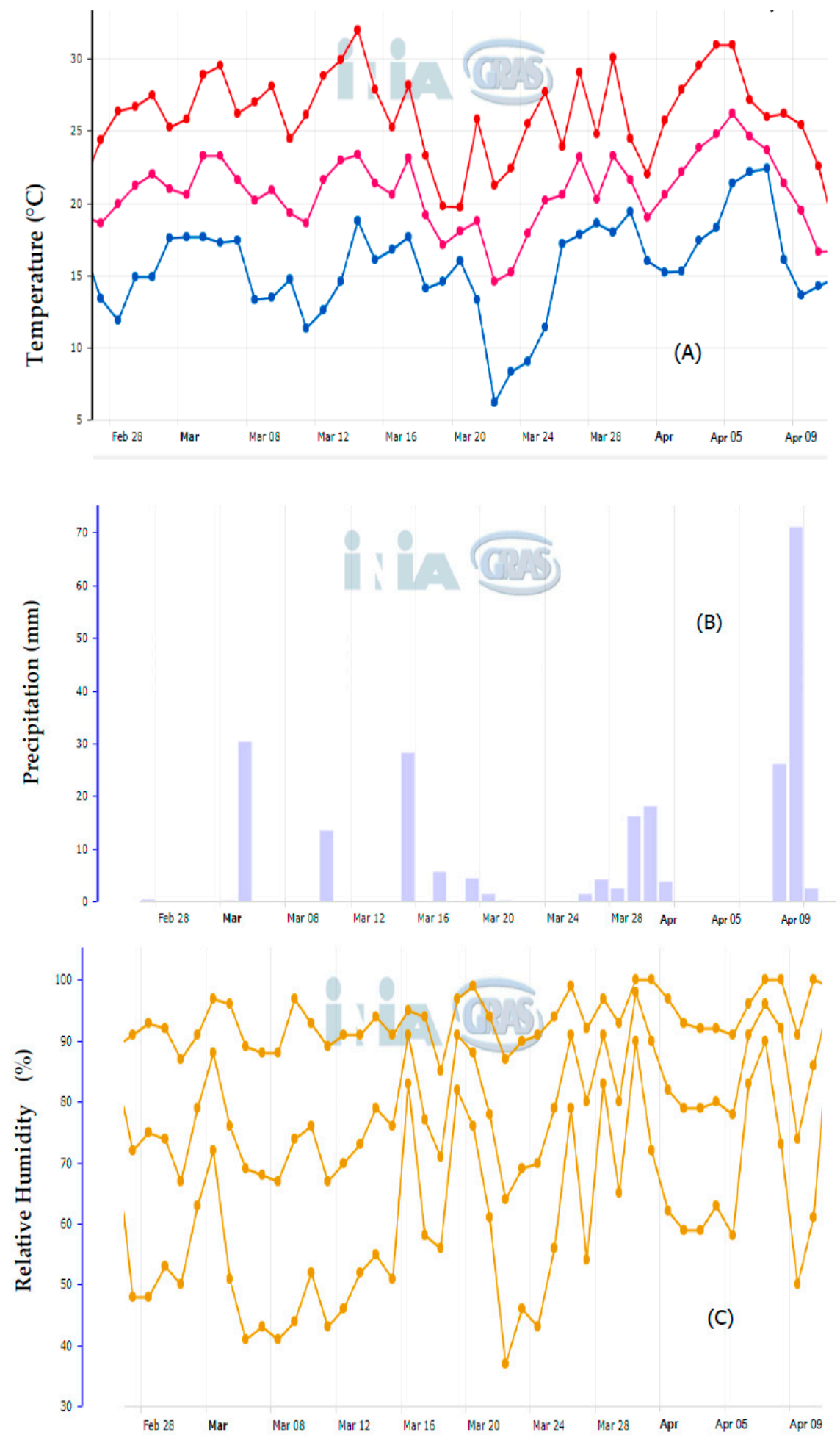

Figure 1. Cont. 


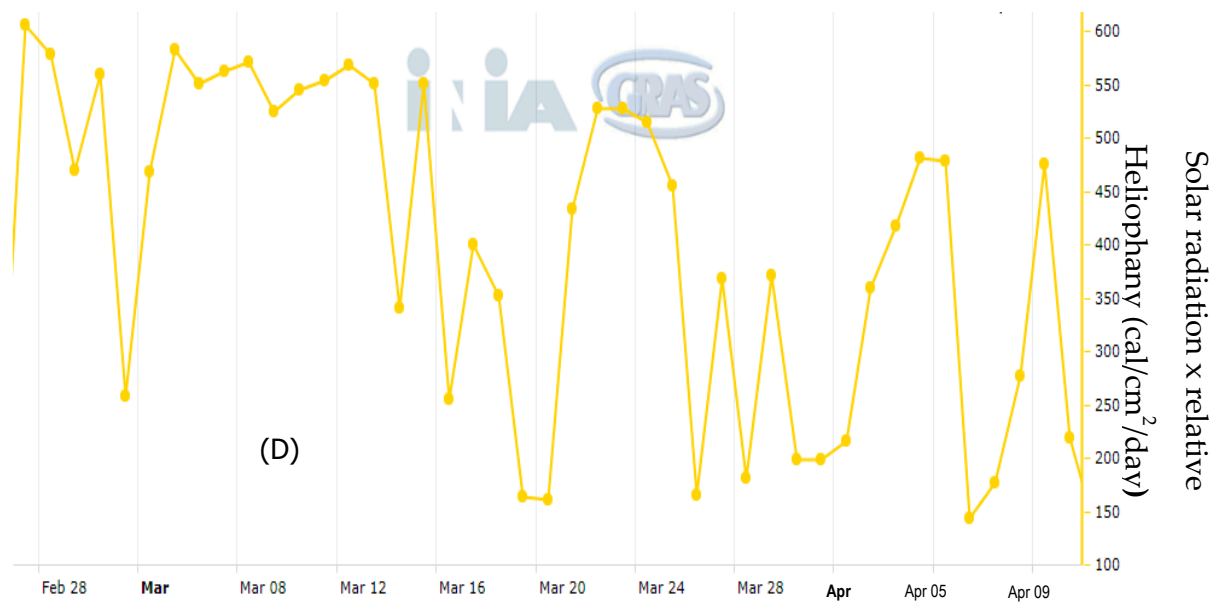

Figure 1. Maximum, average and minimum daily temperature (A), precipitation (B), relative humidity (C) and solar radiation $\mathrm{x}$ relative Heliofania (D).

After harvest, a postharvest treatment simulation was done in an experimental packing line at the National Agricultural Research Institute (INIA) (Salto, Uruguay). In the packing line, imazalil (FUNGAFLOR 75 PS, Janssen Pharmaceutica N.V.) at $1000 \mathrm{mg} \mathrm{L}^{-1}$ was applied in a cascade after hypochlorite sanitation and pre-drying steps. Then, a wax treatment (Brillaqua) was sprayed on the fruit. The treated fruit were air dried and stored for 32 day at $4 \pm 1{ }^{\circ} \mathrm{C}$ and a relative humidity of $96 \pm 1 \%$ in an industrial cold chamber thus simulating the commercial conditions employed for citrus fruit that is exported (Figure 2). The relative humidity and temperature were controlled and recorded daily.

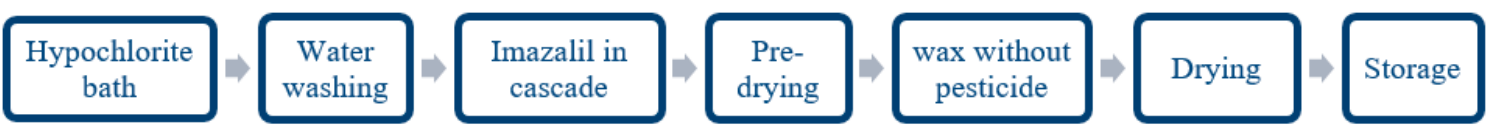

Figure 2. Packing-line pesticide application scheme (postharvest step).

\subsection{Fruit Sampling}

During sampling steps, a fruit blank was taken from untreated trees. From treated trees, sampling was performed following the Codex Alimentarius guidelines [37]. A total of $1 \mathrm{~kg}$ of fruit (approx. 9-10 fruit) was randomly taken by sampling from every part of the canopy (including the central part of the tree) from the six sprayed trees. The first sample was taken $1 \mathrm{~h}$ after pesticide application had dried and labelled as 0 day. Afterward, the fruit were collected randomly at 6, 21, 27 and 35 day after application of the pesticide and at normal harvest (42 day post spraying). Field samples were placed in polyethylene bags and transported on ice to the laboratory for analysis. Each fruit was cut into four pieces, with two opposite pieces selected for analysis. Each sample of two pieces was then homogenized and frozen $\left(-18{ }^{\circ} \mathrm{C}\right)$ in individual polyethylene bags until analysis.

During the postharvest step, treated fruit were placed in plastic boxes and kept in the cold chambers. The individual fruit sampled were weighed before and after the cold storage, and an averaged weight of the fruit was recorded. For the analytical measurement, $1 \mathrm{~kg}$ of fruit (approx. 9-10 units) was taken randomly from the boxes. Samples were taken before and after the packing-line simulation and 32 day after cold storage; thereafter they were analyzed as described previously.

\subsection{LC-MS/MS Operating Conditions}

An Agilent 1200 liquid chromatograph (LC), with quaternary pump, degasser and thermostated autosampler coupled to a triple quadrupole API 4000 (4000 Q-TRAP ABSCIEX) was used for LC-MS/MS analysis. A Zorbax Eclipse XDB-C18 column, $150 \mathrm{~mm}$ long, $4.6 \mathrm{~mm}$ i.d. and $5 \mu \mathrm{m}$ 
particle size, was kept at $40{ }^{\circ} \mathrm{C}$ during the chromatographic analyses. Water/ $\mathrm{HCOOH} 0.1 \%(v / v)$ (A) and acetonitrile (B) were employed as mobile phases at a flow of $0.6 \mathrm{~mL} \mathrm{~min}^{-1}$. The operation of the LC gradient involved the following elution program: starting with $70 \%$ of component $\mathrm{A}$, which was dropped to $0 \%$ in $12 \mathrm{~min}$ ( $3.5 \mathrm{~min}$ hold) then it rose back to $70 \%$ in $1.5 \mathrm{~min}$ ( $4 \mathrm{~min}$ hold) for a total run time of $21 \mathrm{~min} .5 \mu \mathrm{L}$ of each sample were injected.

MS/MS detection was performed in the multiple reaction monitoring (MRM) mode using an electrospray ionization (ESI) interface in the positive ion mode. The optimal MRM transitions, declustering potentials (DP) and collision energies (CE) of each studied compound were determined by infusing the standard solutions directly into the Q-TRAP with a syringe at a constant flow. A retention time window of $90 \mathrm{~s}$ was set for each analyte.

\subsection{Residue Analysis and Method Validation}

Pesticide residues were determined thrice for each sample, using an in-house validated method [38] and quantified by LC-MS/MS operating in MRM mode. Briefly, $10 \mathrm{~g}$ of homogenized sample was weighed into a $50 \mathrm{~mL}$ Teflon centrifugal tube. EtOAc $(10 \mathrm{~mL})$ was added, and the tube was manually shaken for $1 \mathrm{~min}$. Afterwards, $8 \mathrm{~g}$ anhydrous $\mathrm{MgSO}_{4}$ and $1.5 \mathrm{~g} \mathrm{NaCl}$ were added. The tube was shaken vigorously by hand for $1 \mathrm{~min}$, placed in an ultrasonic bath for $15 \mathrm{~min}$, and centrifuged for $10 \mathrm{~min}$ at $3000 \mathrm{rpm}$. After phase separation, $2 \mathrm{~mL}$ of the organic phase was collected in a $4 \mathrm{~mL}$ flask. The extracts were concentrated to dryness under a $\mathrm{N}_{2}$ flow in a $40{ }^{\circ} \mathrm{C}$ water bath. The residue was dissolved in $1 \mathrm{~mL}$ of $\mathrm{MeCN}$ [39].

Prior to analyzing the tissue samples, mandarin blanks (free of pesticide) were fortified at levels of 0.010 and $0.100 \mathrm{mg} \mathrm{kg}^{-1}$ by spiking a standard pesticide working solution in five replicate samples to determine recovery percentages. Precision was calculated as relative standard deviation (RSD) of the five replicates. An external matrix matching the standard method was used for quantification. The matrix effect (ME) was determined for each analyte as: (slope of calibration in matrix - slope of calibration in solvent)/slope of calibration in solvent. All figures of merit were determined.

\subsection{Dissipation Models}

The graphical representation of residue concentration decay over time is known as a pesticide dissipation curve. The residue data gathered from each sampling day and trial were averaged and a linear regression analysis of the data was performed following the procedure in [40]. This methodology allows the evaluation of different "model" equations which describe the dissipation of pesticide residues in agricultural products versus time.

For each pesticide, the experimental residue data was converted to achieve 1st-, 1.5th-, 2nd-order and 1st-order Root Factor (RF) model equations (Table 2). The transformed results were plotted versus time or versus root square time (RF model). The slope, intercept, and the coefficient of determination $\left(R^{2}\right)$ of each linear regression were calculated.

Table 2. Linearizing transformations for the regression equation $y=b x+a$.

\begin{tabular}{ccc}
\hline \multirow{2}{*}{ Function } & \multicolumn{2}{c}{ Transformation } \\
\cline { 2 - 3 } & For $y$ (residue) & For $x$ (time) \\
\hline 1st-order & $\log \mathrm{n}$ & none \\
1.5th-order & $1 / \sqrt{ } \mathrm{R}$ & none \\
2nd-order & $1 / \mathrm{R}$ & none \\
1st-order $\mathrm{RF}^{\mathrm{z}}$ & $\log \mathrm{R}$ & $\sqrt{ } \mathrm{t}$ \\
\hline
\end{tabular}

${ }^{\mathrm{z}} \mathrm{RF}$ : "root function".

The selection of the best fit function from the four possible functions was achieved by comparing the deviations of the experimental values from the back-transformed curve. A modified coefficient 
of determination $\left(\mathrm{r}^{2}\right)$ and $\mathrm{D}$ quantity test were used for that purpose [41]. A test quantity D was calculated as:

$$
\mathrm{D}=/ \mathrm{r} /-\mathrm{t}\left(\mathrm{t}^{2}+(\mathrm{df})\right)^{-0.5}
$$

where $/ \mathrm{r} /$ is the absolute value of the correlation coefficient (from transformed data) and $\mathrm{t}$ is the value of $t$, for $n-2$ (degree of freedom: $d f$ ), of the Student- $t$ distribution table at the contrasted level of probability $(\alpha=0.05)$. If the calculated $\mathrm{D}$ quantity test was greater than zero, the correlation was confirmed. If the modified $\mathrm{r}^{2}$ became negative, the fit was automatically regarded as not assured [40].

\subsection{Data Management and Statistical Analysis}

Data analysis was performed with Biosystems Analyst 1.5 software. Microsoft Excel Data Analysis tool was used for the statistical treatment. Student-test at the contrasted level of probability $(\alpha=0.05)$ was applied.

\section{Results and Discussion}

\subsection{Method Performance}

The main parameters including percentage of recovery, precision, linear calibration, limit of quantification (LOQ) and ME, were investigated according to the EU guidelines. The analytical method was developed to provide a rapid, accurate and efficient way to determine difenoconazole, imidacloprid, pyraclostrobin and spinosad residues in mandarins simultaneously. The results are listed in Table 3. The recovery percentages for the studied pesticides were within the Guidance document on analytical quality control and method validation procedures for pesticide residues and analysis in food and feed (SANTE) criteria (70-120\%) [42].

Table 3. Percentage of recovery ( $\operatorname{Rec} \%$ ), relative standard deviation (RSD \%) at 10 and $100 \mu \mathrm{g} \mathrm{kg}$ concentration levels in mandarin and matrix effects percentage (ME \%).

\begin{tabular}{|c|c|c|c|c|c|}
\hline & \multicolumn{5}{|c|}{ Concentration Level $\left(\mu \mathrm{g} \mathrm{kg}^{-1}\right)$} \\
\hline & \multicolumn{2}{|c|}{10} & \multicolumn{2}{|c|}{100} & \multirow[b]{2}{*}{ ME (\%) } \\
\hline & $\operatorname{Rec}(\%)$ & RSD (\%) & $\operatorname{Rec}^{1}(\%)$ & RSD (\%) & \\
\hline Difenoconazole & $71.8^{z}$ & 8.0 & 88.7 & 7.4 & 8.6 \\
\hline Imidacloprid & 113.4 & 6.6 & 80.9 & 2.5 & -63.5 \\
\hline Pyraclostrobin & 72.1 & 2.1 & 100.0 & 2.2 & 7.2 \\
\hline Spinosad & 86.5 & 3.9 & 98.3 & 15.9 & -55.1 \\
\hline
\end{tabular}

\subsection{Dissipation Studied under Field Conditions}

\section{Best Fitting Model}

The best-fitted model equations for the four pesticides under field conditions on Clementine with their corresponding $\mathrm{r}^{2}$ and $\mathrm{D}$ are presented in Table 4 . The models which best predicts the experimental data forspinosad and difenoconazole were 1st-order equations. Imidacloprid and pyraclostrobin experimental data were best fitted by RF 1st-order and 2nd-order models, respectively. Dissipation curves from experimental data and back-transformed best-fitted models for difenoconazole, imidacloprid, pyraclostrobin and spinosad treatments are presented in Figure 3.

\subsection{Initial Residues, Dissipation Dynamics and Postharvest Storage}

The pesticide residue dissipation in the fruit in the field was studied and the depletion of the active principles was assessed. Similarly, the pesticide residues after the postharvest treatment were 
compared with those found at the end of cold storage. The fruit weight as well as the residue level of pyraclostrobin and difenoconazole remained unchanged after cold storage.

\subsubsection{Difenoconazole}

The initial residue level of difenoconazole was $0.060 \pm 0.011 \mathrm{mg} \mathrm{kg}^{-1}$, which was below the international settled MRL (see Table 1). Difenoconazole dissipated 80\% 42 day after spray application. No significant differences were observed between the concentrations before and after the postharvest steps (Student t-test, $\alpha=0.05$ ) (Figure 4 ).

Table 4. The 1st, 1.5th, 2nd, and Root Factor (RF) 1st order model equations that describe the dissipation of difenoconazole, imidacloprid, pyraclostrobin and spinosad in Clementine mandarin. The Best fitting model for each pesticide are in bold font.

\begin{tabular}{|c|c|c|c|c|}
\hline & Difenoconazole & Imidacloprid & Pyraclostrobin & Spinosad \\
\hline $\begin{array}{c}\text { 1st-order model } \\
\text { Dissipation curve } \\
\mathrm{r}^{2} \\
\mathrm{D}\end{array}$ & $\begin{array}{c}10^{-(0.016 t+1.140)} \\
0.857 \\
0.198\end{array}$ & $\begin{array}{c}10^{-(0.022 t+0.334)} \\
0.883 \\
0.197\end{array}$ & $\begin{array}{c}10^{-(0.008 t+0.591)} \\
0.890 \\
0.124\end{array}$ & $\begin{array}{c}10^{-(0.052 t+0.744)} \\
0.987 \\
0.003\end{array}$ \\
\hline $\begin{array}{c}\text { 1.5th-order model } \\
\text { Dissipation curve } \\
\mathrm{r}^{2} \\
\mathrm{D}\end{array}$ & $\begin{array}{c}1 /(0.116 t+3.353)^{2} \\
0.509 \\
0.167\end{array}$ & $\begin{array}{c}1 /(0.064 t+1.312)^{2} \\
0.951 \\
0.178\end{array}$ & $\begin{array}{c}1 /(0.021 t+1.970)^{2} \\
0.906 \\
0.137\end{array}$ & $\begin{array}{c}1 /(0.301 \mathrm{t}+2.011)^{2} \\
0.871 \\
<0\end{array}$ \\
\hline $\begin{array}{l}\text { 2nd-order model } \\
\text { Dissipation curve } \\
\mathrm{r}^{2} \\
\mathrm{D}\end{array}$ & $\begin{array}{c}1 /(1.491 t+5.617) \\
<0 \\
0.13\end{array}$ & $\begin{array}{c}1 /(0.362 t+0.421) \\
<0 \\
0.124\end{array}$ & $\begin{array}{c}1 /(0.096 t+3.846) \\
0.918 \\
0.149\end{array}$ & $\begin{array}{c}1 /(3.420 \mathrm{t}-1.062) \\
<0 \\
<0\end{array}$ \\
\hline $\begin{array}{l}\text { RF 1st-order model } \\
\text { Dissipation curve } \\
\mathrm{r}^{2} \\
\text { D }\end{array}$ & $\begin{array}{c}10^{-(0.103 \sqrt{ } \mathrm{t}+1.086)} \\
0.598 \\
0.108\end{array}$ & $\begin{array}{c}10^{-(0.148 \sqrt{ } t+0.185)} \\
0.962 \\
0.198\end{array}$ & $\begin{array}{c}10^{-(0.053 \sqrt{ } \mathrm{t}+0.535)} \\
0.893 \\
0.147\end{array}$ & $\begin{array}{c}10^{-(0.242 \sqrt{ } \mathrm{t}+0.658)} \\
0.963 \\
<0\end{array}$ \\
\hline
\end{tabular}

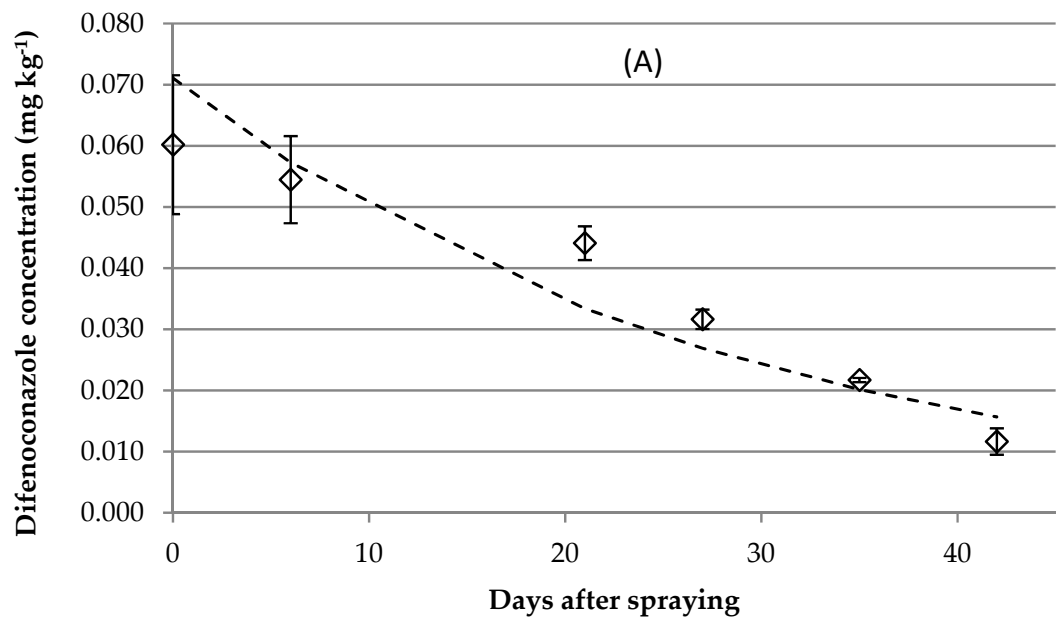

Figure 3. Cont. 

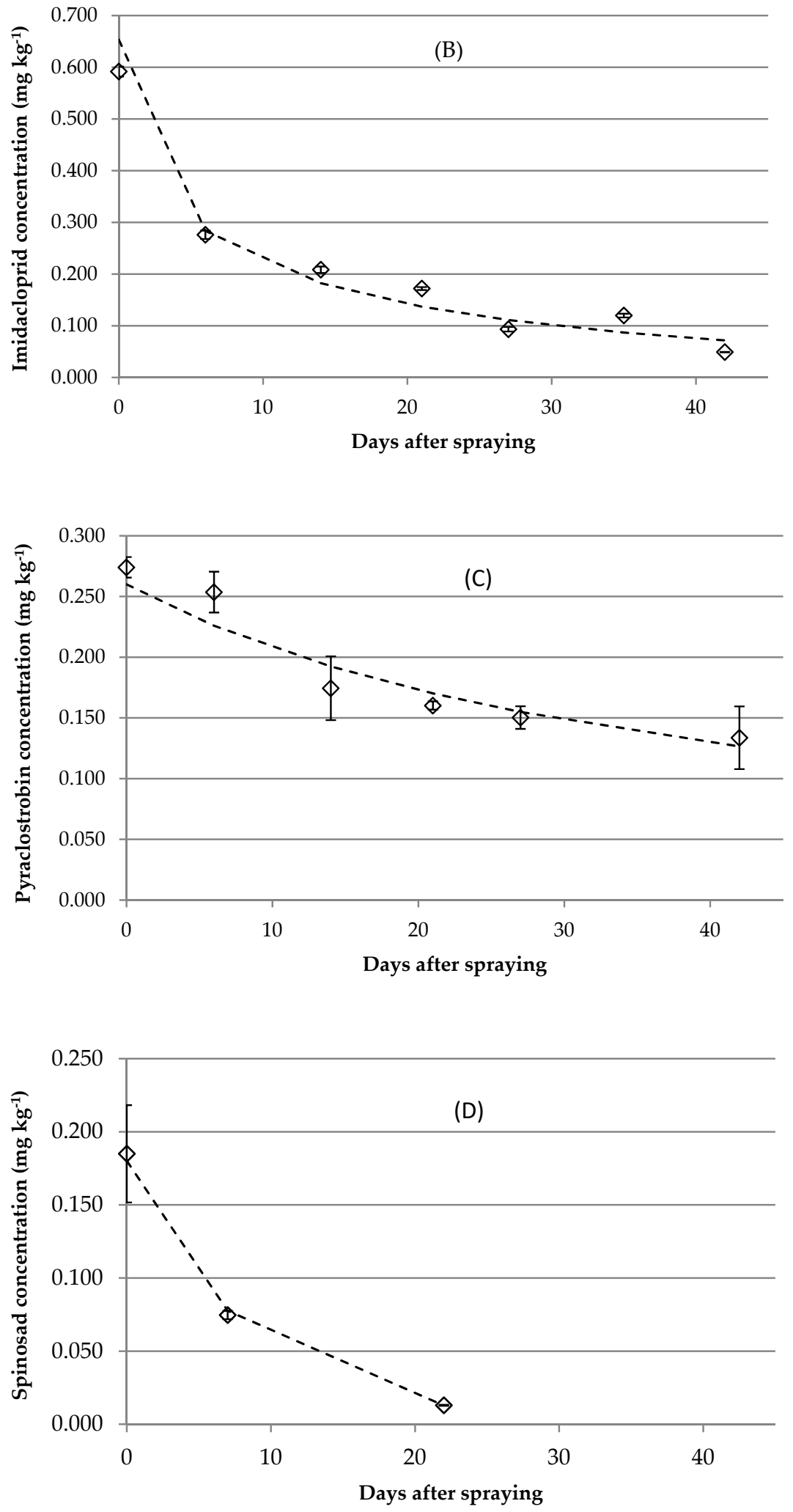

Figure 3. Dissipation curves for difenoconazole (A); imidacloprid (B); pyraclostrobin (C) and spinosad (D) in Clementine mandarin in the days after spraying. $-\checkmark$ - Indicates experimental data. — Indicates the back-transformed dissipation curve (the best-fitted mathematical model: 1st-order equation for $(\mathbf{A}, \mathbf{D})$ Root factor (RF) 1st-order equation for (B) and 2nd-order for (C). 
Harvest time $\equiv$ After packing line $\quad$ After postharvest storage

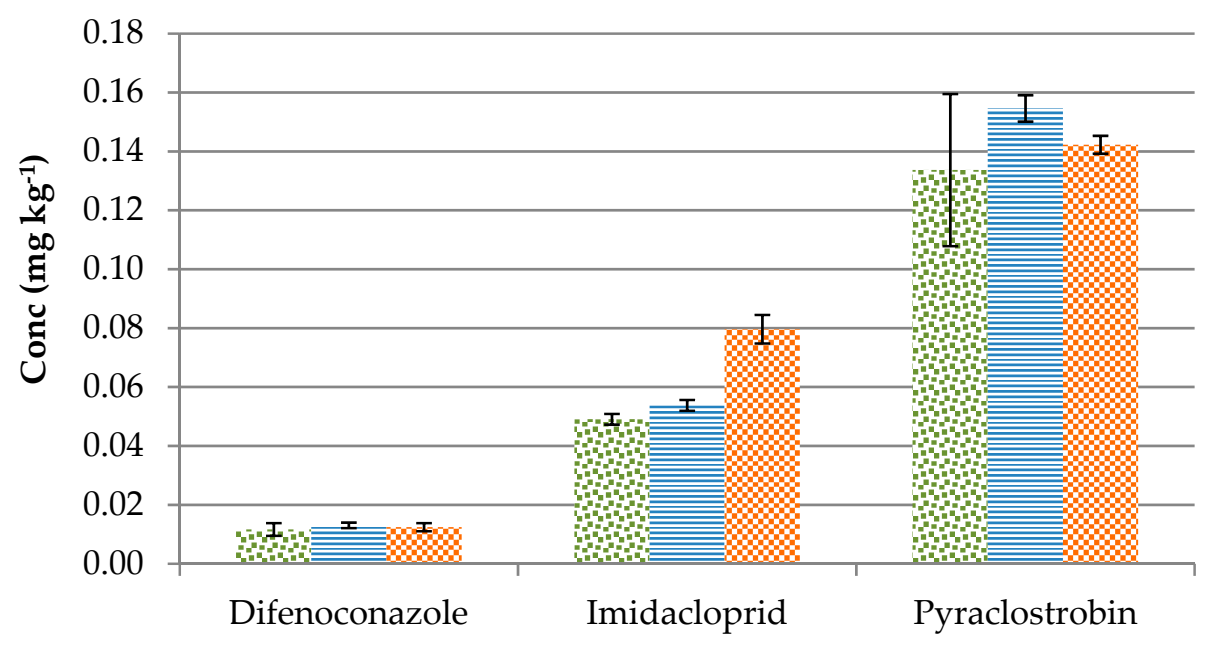

Figure 4. Difenoconazole, imidacloprid and pyraclostrobin residues on Clementine at harvest, after the postharvest packing line and after $32 \mathrm{~d}$ of cold storage. For difenoconazole and pyraclostrobin, no significant differences were detected between the pesticide levels. For imidacloprid residue concentration at the end of the postharvest period differed significantly from the residue level determined at harvest (Student t-test, $\alpha=0.05$ ).

\subsubsection{Imidacloprid}

The initial deposition of imidacloprid on Clementine was $0.592 \pm 0.010 \mathrm{mg} \mathrm{kg}^{-1}$. Imidacloprid residues dissipated $92 \%$ by harvest (42 day after spraying). The final imidacloprid residue concentration at the end of the postharvest period differed significantly from the residue level determined at harvest (Student $t$-test, $\alpha=0.05$ ). No clear conclusion can be made about the effect of cold storage on imidacloprid concentration. The higher levels of imidacloprid detected after cold storage were likely due to fruit water loss, a situation that was observed solely for the imidacloprid-treated mandarins and could be ascribed to some technical failure in the wax treatment. The dehydration of the fruit changed the level of co-extractives and, therefore, the matrix effect also changed. Changes in the matrix effect mean a different slope for the matrix-matched calibration curve, and therefore, in the residue quantitation. Our group established the presence of isobaric compounds that may have interfered with imidacloprid determination in citrus fruit that included mandarins [43]. If this interference was not compensated by the matrix-matched calibration, the imidacloprid levels would be overestimated, yielding higher concentration values for this compound.

\subsubsection{Pyraclostrobin}

At spraying time, the concentration of the studied strobilurin was $0.274 \pm 0.009 \mathrm{mg} \mathrm{kg}^{-1}$. A dissipation of $48 \%$ was observed for pyraclostrobin 42 day after spraying. This fungicide degraded more slowly than the other pesticides. The concentration after postharvest storage did not defer from that at harvest (Student $\mathrm{t}$-test, $\alpha=0.05$ ). Other studies demonstrated the storage stability of pyraclostrobin in commodities with high oil, water and acid content as well as in dry commodities for up to 18 months when stored deep frozen [44].

\subsubsection{Spinosad}

The residue of spinosad on Clementine at application time (day 0) was below the EU and Codex MRLs ( $\left.0.3 \mathrm{mg} \mathrm{kg}^{-1}\right)$. Spinosad residues dissipated below the quantification limit (BQL) of $0.010 \mathrm{mg} \mathrm{kg}^{-1}$ at 28 day after application of treatment. At 22 day after spraying, $93 \%$ of this compound had dissipated. 
The postharvest processes had little influence on the overall dissipation of the pesticides. No significant differences were detected between the pesticide level at the beginning and the end of the packing line. The level was almost unchanged after 32 day in cold storage, except for imidacloprid as explained above.

\subsection{Half-Lives}

According to the best fitting models, difenoconazole and spinosad dissipated following a pseudo 1 st-order kinetics that only was a function of the concentration of the compounds. That means that the concentration declined exponentially and their half-lives, (the time needed to reach half of the initial concentration) remained constant and the clearance times, if needed, could be easily estimated. The half-life of difenoconazole and spinosad were 19.2 and 5.8 day, respectively. Imidacloprid and pyracostrobin half-lives determined with the best fitting models were 4.1 and 39.8 day, respectively. In these cases, the mathematical description of the pesticide dissipation were RF 1st-order and 2nd-order, respectively. These types of decay are concentration-dependent, meaning that the time needed to reach half of the concentration in the fruit (the pesticide half-life) will be a function of the pesticide level on the fruit at the starting time considered.

This is the first report of difenoconazole, spinosad and pyraclostrobin dissipation on Clementine mandarins. Imidacloprid showed almost the same half-life as that previously determined in the rind of sweet orange, which was 3.87 day [35].

Previous reports determined 3.5-5.3 day for the half-life of pyraclostrobin in fruit such as banana [45], strawberry [46], tomato [47], values that are 7 to 10 times lower than those reported in the present work (39.2 day). These results may partially be due to differences between the species, application doses, formulation, local environment, and crop growth characteristics [17-19]. It should be taken into account that citrus fruit have an important wax layer where due to the high octanol/water coefficient (Kow) of this pesticide, it could be retained. These facts could explain the deviation from a normal 1st-order kinetics behavior. It also must be taken into account that pyraclostrobin (pKow = 3.99) could dissolve in the essential oil vesicles of the citrus fruit. The dissolution of the pesticide in the oil sacs would hamper its direct contact with the environment, to which it dissipates. The pesticide that is not solubilized in the essential oil would dissipate quickly from the fruit surface and, afterwards, a slow release from the oil would change the speed of decay of pyraclostrobin.

The determined half-life for spinosad was 5.8 day. The short $t_{1 / 2}$ of this insecticide is influenced by light, especially the ultraviolet (UV) component [48]. Also, residue decline may be attributed to hydrolysis, biodegradation, or growth dilution [49]. Although there are no specific studies of dissipation of spinosad on mandarins reported in literature similar values of half-lives are reported for this pesticide in other vegetables and fruit. Values in the range of 3.5-3.9 day for zucchini [50], 1.7 day for tomato [51] and 1.4 day for cabbage [52] have been reported.

\subsection{Estimating Storage Effect on Pesticide Level}

The equations of the dissipation models allowed the estimation of the influence of the postharvest process through the comparison between the pesticide levels obtained after washing, imazalil and wax application and the final cold storage and the calculated ones after $32 \mathrm{~d}$ of postharvest storage. The expected concentration values, applying the best fitting models versus actual ones after cold storage at $74 \mathrm{~d}$ after spraying were: 0.005 versus $0.012 \mathrm{mg} \mathrm{kg}^{-1}$ for difenoconazole, 0.035 versus $0.080 \mathrm{mg}$ $\mathrm{kg}^{-1}$ for imidacloprid and 0.091 versus $0.142 \mathrm{mg} \mathrm{kg}^{-1}$ for pyraclostrobin, respectively. Therefore, cold storage slowed down the dissipation of these pesticides.

\section{Conclusions}

The dissipation pattern of two fungicides and two insecticides on Clementine mandarin was studied. The dynamics of the decay of difenoconazole, imidacloprid, pyraclostrobin, and spinosad in field conditions was unique for each one. However, in all cases, a clear dissipation trend could be 
drawn. Spinosad decomposition was the most rapid, dissipating to below the quantification limit of $0.010 \mathrm{mg} \mathrm{kg}^{-1} 28$ day after spraying. Pyraclostrobin showed the lowest dissipation rate under the field conditions. It was the highest persistence period reported for pyraclostrobin on fruit to date. For all four pesticides, the postharvest stage did not diminish the pesticide residue concentrations, which were below their MRLs before entering in the postharvest phase. These results support their safe use in Clementine cropping under the studied conditions.

Author Contributions: N.B. contributed in the design of the study, ran the laboratory work, processed the data and drafted the paper. E.L. and P.P. carried out the pesticide applications, sampling, harvest and postharvest treatment. V.C. collaborated in laboratory work, data analysis and critically read and adjusted the manuscript. F.R. and H.H. gave the conceptual frame of project, supervised the design of the study and adjusted the final version of the manuscript. All the authors have read the final manuscript and approved the submission.

Funding: This research was funded by Instituto Nacional de Investigación Agropecuaria (INIA), grant number L2_12_1_VI_CT_GT4_7639.

Acknowledgments: N. Besil be grateful to Agencia Nacional de Investigación e Innovación for her scholarship POS_NAC_2012_1_9348 and Programa de Apoyo a las Ciencias Básicas (PEDECIBA). The authors are grateful to Instituto Nacional de Investigación Agropecuaria for logistical support and Eng. Franco Bologna for technical assistance.

Conflicts of Interest: The authors declare no conflict of interest.

\section{References}

1. Liu, Y.; Heying, E.; Tanumihardjo, S.A. History, Global Distribution, and Nutritional Importance of Citrus Fruits. Compr. Rev. Food Sci. Food Saf. 2012, 11, 530-545. [CrossRef]

2. FAO. FAOSTAT. Available online: http://www.fao.org/faostat/en/\#data/QC/visualize (accessed on 6 September 2018).

3. DIEA. Anuario Estadístico Agropecuario, 20th ed.; MGAP: Montevideo, Uruguay, 2017.

4. Shinde, S.; Neharkar, P.; Dhurve, N.; Sawai, H.; Lavhe, N.; Masolkar, D. Evaluation of different insecticides against citrus leaf miner on Nagpur mandarin. J. Entomol. Zool. Stud. 2017, 5, 1889-1892.

5. Rodríguez, V.A.; Avanza, M.M.; Mazza, S.M.; Giménez, L.I. Pyraclostrobin effect to control of citrus black spot. Summa Phytopathol. 2010, 36, 334-337. [CrossRef]

6. Timmer, L.W.; Peever, T.; Solel, Z.; Akimitsu, K. Alternaria Diseases of Citrus-Novel Pathosystems. Phytopathol. Mediter. 2003, 42, 99-112.

7. Altieri, G.; Di Renzo, G.C.; Genovese, F.; Calandra, M.; Strano, M.C. A new method for the postharvest application of imazalil fungicide to citrus fruit. Biosyst. Eng. 2013, 115, 434-443. [CrossRef]

8. Lado, J.; Manzi, M.; Silva, G.; Luque, E.; Blanco, O.; Pérez, E. Effective alternatives for the postharvest control of imazalil resistant Penicillium digitatum strains. Acta Hortic. 2010, 877, 1449-1456. [CrossRef]

9. Boina, D.R.; Bloomquist, J.R. Chemical control of the Asian citrus psyllid and of huanglongbing disease in citrus. Pest Manag. Sci. 2015, 71, 808-823. [CrossRef] [PubMed]

10. Farha, W.; Abd El-Aty, A.M.; Rahman, M.M.; Shin, H.C.; Shim, J.H. An overview on common aspects influencing the dissipation pattern of pesticides: A review. Environ. Monit. Assess. 2016, 188. [CrossRef] [PubMed]

11. Navarro, S.; Oliva, J.; Navarro, G.; Barba, A. Dissipation of chlorpyrifos, fenarimol, mancozeb, metalaxyl, penconazole, and vinclozolin in grapes. Am. J. Enol. Vitic. 2001, 52, 35-40.

12. Karmakar, R.; Kulshrestha, G. Persistence, metabolism and safety evaluation of thiamethoxam in tomato crop. Pest Manag. Sci. 2009, 65, 931-937. [CrossRef] [PubMed]

13. Picó, Y.; El-Sheikh, M.A.; Alfarhan, A.H.; Barceló, D. Target vs non-target analysis to determine pesticide residues in fruits from Saudi Arabia and influence in potential risk associated with exposure. Food Chem. Toxicol. 2018, 111, 53-63. [CrossRef] [PubMed]

14. Chen, M.; Tao, L.; McLean, J.; Lu, C. Quantitative Analysis of Neonicotinoid Insecticide Residues in Foods: Implication for Dietary Exposures. J. Agric. Food Chem. 2014, 62, 6082-6090. [CrossRef] [PubMed]

15. Suárez-Jacobo, A.; Alcantar-Rosales, V.M.; Alonso-Segura, D.; Heras-Ramírez, M.; Elizarragaz-De La Rosa, D.; Lugo-Melchor, O.; Gaspar-Ramirez, O. Pesticide residues in orange fruit from citrus orchards in Nuevo Leon State, Mexico. Food Addit. Contam. Part B 2017, 10, 192-199. [CrossRef] [PubMed] 
16. Ortelli, D.; Patrick, E.; Corvi, C. Pesticide residues survey in citrus fruits. Food Addit. Contam. 2005, 22, 423-428. [CrossRef] [PubMed]

17. Fantke, P.; Gillespie, B.W.; Juraske, R.; Jolliet, O. Estimating Half-Lives for Pesticide Dissipation from Plants. Environ. Sci. Technol. 2014, 48, 8588-8602. [CrossRef] [PubMed]

18. Fantke, P.; Juraske, R. Variability of pesticide dissipation half-lives in plants. Environ. Sci. Technol. 2013, 47, 3548-3562. [CrossRef] [PubMed]

19. Hanson, B.; Bond, C.; Buhl, K.; Stone, D. Pesticide Half-life Fact Sheet. Available online: http:/ / npic.orst. edu/factsheets/half-life.html (accessed on 24 August 2018).

20. Lewis, K.; Tzilivakis, J. Development of a data set of pesticide dissipation rates in/on various plant matrices for the Pesticide Properties Database (PPDB). Data 2017, 2, 28. [CrossRef]

21. Wang, C.; Qiu, L.; Zhao, H.; Wang, K.; Zhang, H. Dissipation dynamic and residue distribution of flusilazole in mandarin. Environ. Monit. Assess. 2013, 185, 9169-9176. [CrossRef] [PubMed]

22. Chen, W.; Jiao, B.; Su, X.; Zhao, Q.; Sun, D. Dissipation and residue of 2,4-d in citrus under field condition. Environ. Monit. Assess. 2015, 187. [CrossRef]

23. Zhang, Q.; Chen, Y.; Wang, S.; Yu, Y.; Lu, P.; Hu, D.; Yang, Z. Dissipation, residues and risk assessment of spirotetramat and its four metabolites in citrus and soil under field conditions by LC-MS/MS. Biomed. Chromatogr. 2018, 32. [CrossRef] [PubMed]

24. Sun, D.; Zhu, Y.; Pang, J.; Zhou, Z.; Jiao, B. Residue level, persistence and safety of spirodiclofen-pyridaben mixture in citrus fruits. Food Chem. 2016, 194, 805-810. [CrossRef] [PubMed]

25. Payá, P.; Oliva, J.; Cámara, M.A.; Barba, A. Dissipation of insect growth regulators in fresh orange and orange juice. Commun. Agric. Appl. Biol. Sci. 2007, 72, 161-169. [PubMed]

26. Waks, J.; Schiffmann-Nadel, M.; Lomaniec, E.; Chalutz, E. Relation between fruit waxing and development of rots in citrus fruit during storage. Plant Dis. 1985, 69, 869-870. [CrossRef]

27. Vicent, A.; Armengol, J.; García-Jiménez, J. Rain fastness and persistence of fungicides for control of alternaria brown spot of citrus. Plant Dis. 2007, 91, 393-399. [CrossRef]

28. Miles, A.K.; Willingham, S.L.; Cooke, A.W. Field evaluation of strobilurins and a plant activator for the control of citrus black spot. Aust. Plant Pathol. 2004, 33, 371-378. [CrossRef]

29. Dong, F.; Li, J.; Chankvetadze, B.; Cheng, Y.; Xu, J.; Liu, X.; Li, Y.; Chen, X.; Bertucci, C.; Tedesco, D.; et al. Chiral Triazole Fungicide Difenoconazole: Absolute Stereochemistry, Stereoselective Bioactivity, Aquatic Toxicity, and Environmental Behavior in Vegetables and Soil. Environ. Sci. Technol. 2013, 47, 3386-3394. [CrossRef] [PubMed]

30. Balba, H. Review of strobilurin fungicide chemicals. J. Environ. Sci. Health Part B 2007, 42, 441-451. [CrossRef] [PubMed]

31. Simon-Delso, N.; Amaral-Rogers, V.; Belzunces, L.P.; Bonmatin, J.M.; Chagnon, M.; Downs, C.; Furlan, L.; Gibbons, D.W.; Giorio, C.; Girolami, V.; et al. Systemic insecticides (neonicotinoids and fipronil): Trends, uses, mode of action and metabolites. Environ. Sci. Pollut. Res. Int. 2015, 22, 5-34. [CrossRef] [PubMed]

32. Miles, M. The effects of spinosad, a naturally derived insect control agent to the honeybee. Bull. Insectol. 2003, 56, 119-124.

33. West, S.D.; Turner, L.G. Determination of spinosad and its metabolites in citrus crops and orange processed commodities by HPLC with UV detection. J. Agric. Food Chem. 2000, 48, 366-372. [CrossRef] [PubMed]

34. Phartiyal, T.; Srivastava, R.M. Dissipation of imidacloprid on lemon fruit rind under tarai agro-climatic condition of Uttarakhand. J. Entomol. Res. 2014, 38, 285-288.

35. Singh, N.; Bisht, S.; Yadav, G.; Kamari, B. Dissipation of imidacloprid on sweet orange fruits. Int. J. Chem. Stud. 2017, 5, 683-686.

36. Saunt, J. Citrus Varieties of the World; Sinclair Intl Business Resources: Norwich, UK, 2000.

37. Codex. Recommended Methods of Sampling for the Determination of Pesticide Residues for Compliance with MRLs CAC/GL 33-199; Codex: New Delhi, India, 1999.

38. Besil, N.; Pareja, L.; Colazzo, M.; Niell, S.; Rodríguez, A.; Cesio, V.; Heinzen, H. GC-MS method for the determination of 44 pesticides in mandarins and blueberries. In Proceedings of the 3rd Latin American Pesticide Residue Workshop, Food and Environment, Montevideo, Uruguay, 8-11 May 2011; p. 156.

39. Besil, N.; Pérez-Parada, A.; Cesio, V.; Varela, P.; Rivas, F.; Heinzen, H. Degradation of imazalil, orthophenylphenol and pyrimethanil in Clementine mandarins under conventional postharvest industrial conditions at $4{ }^{\circ} \mathrm{C}$. Food Chem. 2016, 194, 1132-1137. [CrossRef] [PubMed] 
40. Timme, G.; Frehse, H.; Laska, V. Statistical interpretation and graphic representation of the degradation behavior of pesticide residues II. Pflanzenschutz-Nachrichten Bayer 1986, 39, 187-203.

41. Timme, G.; Frehse, H. Statistical interpretation and graphic representation of the degradation behaviour of pesticide residues. 1. Pflanzenschutz-Nachrichten Bayer 1980, 33, 47-60.

42. European. Guidance Document on Analytical Quality Control and Method Validation Procedures for Pesticides Residues Analysis in Food and Feed; Document SANTE/11945/2015; European Commission: Brussels, Belgium, 2015.

43. Besil, N.; Cesio, V.; Heinzen, H.; Fernandez-Alba, A.R. Matrix Effects and Interferences of Different Citrus Fruit Coextractives in Pesticide Residue Analysis Using Ultrahigh-Performance Liquid Chromatography-High-Resolution Mass Spectrometry. J. Agric. Food Chem. 2017, 65, 4819-4829. [CrossRef] [PubMed]

44. EFSA. Modification of the existing MRLs for pyraclostrobin in various crops. EFSA J. 2011, 9, 2120. [CrossRef]

45. Yang, M.; Zhang, J.; Zhang, J.; Rashid, M.; Zhong, G.; Liu, J. The control effect of fungicide pyraclostrobin against freckle disease of banana and its residue dynamics under field conditions. J. Environ. Sci. Health Part $B$ 2018. [CrossRef] [PubMed]

46. Wang, Z.; Cang, T.; Qi, P.; Zhao, X.; Xu, H.; Wang, X.; Zhang, H.; Wang, X. Dissipation of four fungicides on greenhouse strawberries and an assessment of their risks. Food Control 2015, 55, 215-220. [CrossRef]

47. Jankowska, M.; Kaczynski, P.; Hrynko, I.; Lozowicka, B. Dissipation of six fungicides in greenhouse-grown tomatoes with processing and health risk. Environ. Sci. Pollut. Res. 2016, 23, 11885-11900. [CrossRef] [PubMed]

48. Adak, T.; Mukherjee, I. Investigating Role of Abiotic Factors on Spinosad Dissipation. Bull. Environ. Contam. Toxicol. 2016, 96, 125-129. [CrossRef] [PubMed]

49. Jacobsen, R.E.; Fantke, P.; Trapp, S. Analysing half-lives for pesticide dissipation in plants. SAR QSAR Environ. Res. 2015, 26, 325-342. [CrossRef] [PubMed]

50. Liu, Y.; Sun, H.; Wang, S. Dissipation and residue of spinosad in zucchini under field conditions. Bull. Environ. Contam. Toxicol. 2013, 91, 256-259. [CrossRef] [PubMed]

51. Ramadan, G.; Shawir, M.; El-Bakary, A.; Abdelgaleil, S. Dissipation of four insecticides in tomato fruit using high performance liquid chromatography and QuECHERS methodology. Chilean J. Agric. Res. 2016, 76, 129-133. [CrossRef]

52. Singh, S.; Battu, R.S. Dissipation kinetics of spinosad in cabbage (Brassica oleracea L.var. capitata). Toxicol. Environ. Chem. 2012, 94, 319-326. [CrossRef] 